\title{
FEDERALISMO E MUNICIPALIZAÇÃO: UMA DISCUSSÃO À LUZ DAS GRAMÁTICAS POLÍTICAS BRASILEIRAS
}

\author{
FEDERALISM AND MUNICIPALISATION: A DISCUSSION IN \\ THE LIGHT OF THE BRAZILIAN POLITICAL GRAMMARS
}

Ladice Cristina Bezerra de Almeida Costa ${ }^{1}$

Lígia Gonçalves de Lima ${ }^{2}$

Lucelena Alves de Oliveira ${ }^{3}$

Mestranda pelo Programa de Pós-Graduação em Gestão Pública para o Desenvolvimento do Nordeste (MGP) Especialista em Gestão Pública pelo Instituto Federal de Pernambuco Recife - PE

e-mail: ladice.costa@ufrpe.br

2

Mestranda pelo Programa de Pós-Graduação em Gestão Pública para o Desenvolvimento do Nordeste (MGP) Especialista em Gestão Pública pela Faculdade Joaquim Nabuco Recife - PE e-mail: ligiaglima@ yahoo.com.br

Mestranda pelo Programa de Pós-Graduação em Gestão Pública para o Desenvolvimento do Nordeste (MGP) Especialista em Administração e Marketing na Universidade Federal Rural de Pernambuco

Recife - PE

e-mail: lucelena.

oliveira@ufrpe.br
Resumo: O Federalismo é a forma de Estado do Brasil desde que se tornou República. Em um País de grandes extensões territoriais e de diversidades presentes em todas as regiões esse modelo é o mais adequado. Mas ao mesmo tempo em que ocorria o deslocamento de poder para as localidades, apresentava-se ao federalismo o jeitinho tupiniquim de práticas e concepções políticas, que se tornariam verdadeiras mazelas no exercício do poder público e no desenvolvimento político nacional. As gramáticas políticas brasileiras, das quais se destaca o clientelismo, vêm sendo cenários nas relações de poder entre os entes federativos. Após a Constituição de 1988, as relações clientelistas receberam um reforço com o advento da Municipalidade e uma das moedas de troca entre os poderes local e geral são as transferências governamentais. Objeto de discussão nesse artigo, o Fundo de Participação dos Municípios se mostra uma estratégia ineficaz levando as prefeituras ao ciclo vicioso de dependência financeira. O fundo, além de arcar apenas e tão somente com os custos da máquina administrativa, agencia a ingovernabilidade municipal e a incapacidade de autossustentação. A proposta inicial do Federalismo em promover o combate às desigualdades, que seria uma "revolução", por fim se dobrou ao velho e corrompido sistema político brasileiro de sempre.

palavras-chaves: Federalismo; Gramática Política; Clientelismo; Municipalidade; Fundo de Participação dos Municípios.

ABstract: Federalism is the form the State of Brazil since becoming a Republic. In a Country of large territorial extensions and diversity present in all regions in this model is the most appropriate. But at the same time was the shift of power to localities, presented to the federalism the tupiniquim way of political conceptions and practices become true evils in the exercise of State authority and political development National. Brazilian policy grammars, of which stands out the patronage, has been setting in the power relations between the federative entities. After the Constitution of 1988, clientelistic relations received reinforcement with the advent of the municipality and one of the pieces of exchange between local and General powers are government transfers. Object of discussion in this article, the participation of Municipalities if shows an ineffective strategy in the prefectures to the vicious cycle of financial dependency. The Fund in addition to afford only and so only the costs of the administrative machinery, promotes the ungovernability and the inability of self-sufficiency. The initial proposal of federalism to promote the fight against inequality, it would be a "revolution", finally folded to the old and corrupt political system always Brazilian.

KEYwORDs: Federalism; Political Grammar; Patronage; Municipality; Participation of the municipalities Fund. 


\section{INTRODUÇÃO}

A forma de Estado, ou a maneira como se dá o exercício de Poder em razão da base territorial do Estado Brasileiro, é o Federalismo. Modelo recomendável, uma vez que o Brasil é um país de grandes extensões territoriais, de diversidades culturais, climáticas, sociais e econômicas, onde necessidades e prioridades diferem entre regiões. Foi implantado um pouco após a proclamação da República, por determinação do Governo Central, para acalmar as elites regionais que reivindicavam menos centralismo monárquico. Desde então, muito foi vivenciado historicamente, mas ainda está por se descobrir a eficácia desse modelo federal no Brasil, e muito disso por culpa da cultura política que se choca com os princípios puros do federalismo.

O Pacto Federativo do Brasil, atualmente, tem como característica a concentração de poder no Executivo junto com o poder Legislativo bicameral, outrossim, tem-se partidos políticos atrelados à interesses regionais, e, principalmente, o peso dos grandes níveis de desigualdade socioeconômica, tanto em nível individual como regional. Esse cenário gera algumas particularidades na distribuição de competências, que não vem sendo tão vantajosas ou otimizando tanto os ganhos para os entes federativos. Com a reestrutura do pacto federativo trazida pela Constituição Federal de 1988, e o município sendo prestigiado no Federalismo, o mote era colocar o orçamento a serviço de uma melhor qualidade de vida para os cidadãos. Esperava-se uma autonomia financeira, que provesse cada município da capacidade de subsidiar seus gastos públicos e prestar serviços adequados com eficiência. Recursos financeiros próprios e prerrogativas legislativas amplas para solucionar os problemas e planejar o desenvolvimento da região. Escola Nacional de Administração Pública - ENAP (2018). Mas o cenário político brasileiro tem características peculiares, que influenciam diretamente na ideia original de colocar a municipalidade como estrela do pacto federativo, e nem tudo do que se resulta hoje, era igual ao planejado.

Baseado na observação que o desenho do pacto federativo versus municipalização precisa ser revisto, esse artigo propõe uma discussão temática à luz das gramáticas políticas do Brasil. Para tanto se utiliza da revisão de literatura sobre o federalismo, sobre o pacto federativo e a relação do tema com as gramáticas políticas. No intuito de esboçar a discussão tem-se também a análise dos 18 municípios criados após 1988, no Estado de Pernambuco. Um passeio por seus índices socioeconômicos relevantes, pela configuração e formato das suas receitas orçamentárias, com ênfase no fundo de Participação dos Municípios e na arrecadação tributária do Imposto sobre Serviços. Um produto que não vem tendo a simetria desejada e que provocou a inquietação desse estudo, no tocante à falta de esforço fiscal das prefeituras, a ingerência fortemente presente e as velhas práticas clientelistas e corporativistas, que teimam em se perpetuar colocando em xeque $o$ modelo do federalismo brasileiro. 
O Decreto n. 1, de 15 de novembro de 1889, criou a Federação brasileira e segundo Martins (2017), serviu como uma espécie de Constituição provisória até que foi editada a Constituição definitiva em 1891. Antes disso, o Brasil era um estado unitário e seu território era dividido em províncias. Além de estabelecer a forma de governo republicano, em oposição ao regime monarquista vigente, a Constituição Federal também criou Estados-Membros autônomos. Muito embora, segundo Nunes (2003), a República Federativa, ainda tinha um pé na colonização, uma vez que:

Os estados e municípios, com raras exceções, não eram mais do que organizações feudais nas quais a sucessão política permanecia como privilégio privado. Os negócios públicos e os negócios privados, domésticos, eram tratados da mesma forma e, muitas vezes, acontecia que os últimos determinavam a solução dos primeiros.

A desagregação, que deslocava para as regiões a autonomia, vislumbrava saciar a fome de poder das elites locais. Holanda (1947), quando fala de Estado, lembra que "não é uma ampliação do círculo familiar e, ainda menos, uma integração de certos agrupamentos, certas vontades particulares", mas foi nesse cenário patrimonialista, que se deu início o sistema federalista brasileiro. Em tempos de coronelismo, a organização do Estado em novos moldes deu plenos poderes, não de direito, mas de fato, as oligarquias locais. Na República Velha os governadores fomentavam alianças políticas entre o poder local e o poder estadual. Junto excitavam também relações entre poder público e interesses privados. Apresentava-se ao federalismo o jeitinho tupiniquim de práticas e concepções políticas, que se tornariam verdadeiras mazelas no exercício do poder público e no desenvolvimento político nacional. Práticas essas ainda arraigadas nos mais diversos campos da vida política, como o clientelismo.

Segundo Nunes (2003), nas sociedades rurais, que foram o berço do federalismo no Brasil, o clientelismo residia em uma troca generalizada entre patrons e clientes. Relação desigual, onde os clientes se encontram em total subordinação, por não possuir terras. Isso suscita numa reciprocidade vertical: "gera uma série de laços pessoais entre eles, que vão desde o simples 'compadrio' à proteção e lealdade política". Ressalta-se que "o patron é o ator que tem contato com o mundo exterior e tem comando sobre recursos políticos". E "é o patron que tem recursos - internos e externos à comunidade - dos quais dependem os clientes". Assim se dão, nesse período, as relações federalistas, entre Governo central e local. Os detentores do poder local se reportando aos recursos federais para nutrir suas relações clientelistas, não caracterizadas por ser de interesse coletivo. 
Nunes (2003) quando analisou a política brasileira e sua relação com a sociedade identificou o que chamaria de gramática política (Clientelismo, Corporativismo, Insulamento Burocrático e Universalidade de procedimentos). Como visto acima uma das gramáticas se firmou juntamente com o Estado Federal e sua descentralização. O ideário federalista sofre golpes, pois o clientelismo se abaliza, basicamente, pelo fato de ter natureza personalista, em que as relações políticas possuem um caráter proeminentemente pessoal. Afeta o interesse público e a distribuição social dos recursos do País em favor de interesses de ordem privada, privilegiando os eleitores que vão trocar votos por favores pessoais. Em outras palavras, o clientelismo prejudica em termos estruturais a organização do setor público e do Estado durante toda a história brasileira. Uma mácula no federalismo.

Nem mesmo a crise de 1929 e a reversão da descentralização do poder no governo de Getúlio Vargas, fez com que as relações políticas entre o Estado e sociedade deixassem de ser a fragilidade do federalismo. Marcada pelo esgotamento do liberalismo econômico e político, com sérios reflexos no Brasil, a crise aqui, teve seu ápice com a "Revolução de 1930" e, por conseguinte, a implantação da Era Vargas (1930-1945). Período assinalado pela expansão de regimes autoritários, altamente centralizadores, onde a autonomia dos Estados quase chega a inexistir. Getúlio Vargas outorgou uma Constituição, imposta sob a força militar, irrompeu com a ordem constitucional, dissolveu o Congresso Nacional e declarou o Estado Novo. A República Federativa vigorava só no papel, mas mesmo assim a oligarquia não deixa de assombrar e mais uma gramática política se instaura: o corporativismo. Conforme Nunes (2003), "os corporativistas, tem o Estado como uma organização com interesses estabelecidos, um ator principal, lado a lado com os grupos". Nesse ínterim:

O novo regime implementou a centralização mas teve de contentar, ao mesmo tempo, os grupos rurais, os grupos industriais emergentes, os militares, os profissionais de classe media e os operários. Isto significou a desagregação das políticas estatais em muitas direções diferentes.

Sendo assim, ao invés de destituir as bases locais e o clientelismo da República velha, o Estado, não tão Novo como propunha, sustentou-se nele para conseguir apoio e lidar com todas as questões. Portanto, como narra Nunes (2003): "centralização e corporativismo não conseguiram destruir o clientelismo. Ao contrario geraram novos recursos para sua prática, agora administrados pelo governo federal". Corporativismo e clientelismo coexistiram e se ajudaram mutuamente, desenhando as relações da federação brasileira nesse período.

Após a Era Vargas, o processo de redemocratização não afastou a influência das gramáticas políticas, pois conforme Nunes (2003):

“O corporativismo, já se encontrava em pleno funcionamento ao lado da antiga, o clientelismo. Os novos partidos 
políticos, criados com a redemocratização, fizeram largo uso do clientelismo em seu processo de constituição, renovando e reforçando, portanto, esta antiga gramática".

Soma-se a esse cenário a questão mor da Constituição Federal de 1946, que era tratar as disparidades sociais e regionais cultivadas até então. Caráter esse nem tão espontâneo, mas, sobretudo imposto por forças externas, como comenta Bercovici (2004):

A Questão Regional ganhou importância no debate político nacional, com a concepção de que a atuação estatal e o planejamento eram elementos essenciais para o desenvolvimento, de acordo com as diretrizes elaboradas pela recém-criada CEPAL (Comissão Econômica para América Latina).

A descentralização novamente estrela do federalismo, ganhou como respaldo instituições como a SUDAM (Superintendência para o Desenvolvimento da Amazônia) e a SUDENE (Superintendência para o Desenvolvimento do Nordeste). Porém, o que parecia trazer um federalismo mais "funcional", que delegaria às forças políticas de caráter regional e local a possibilidade de revogação das diferenças pontuais, na verdade, com essas instituições, trouxe o fomento às gramáticas políticas. A SUDENE e a SUDAN, e mais outras instituições desse cunho, não cumpriram exatamente o papel previsto e o que se viu no lugar da eficiência foi criação de "cabides de emprego", para que políticos alocassem familiares e amigos.

Passado o período de redemocratização, o Federalismo sofre outro golpe contra sua organização e a descentralização do poder, que foi reflexo dos acontecimentos de 1964. A Constituição, outorgada pelo regime militar em 1967, manteve a forma de Estado em uma federação, porém estabeleceu mecanismos que fortaleceu o poder central. Segundo Brito (2012), a União além de comandar a organização político-administrativa de todo o sistema federal, também chegava a legislar. O ápice da redução drástica da autonomia estadual foi o Ato Institucional $\mathrm{n}^{0} 5$. O decreto deixou os entes federados dependentes de recursos provenientes da União, sem autossuficiência fiscal.

O federalismo e a democracia não coadunavam com o Regime Militar. Entretanto, essa centralidade burocrática durante o regime militar não foi uniforme. Nunes (2003) chama a atenção que apesar de uma parte da cúpula do regime ter agido na intenção de estabelecer um alto grau de autonomia, tanto para as decisões burocráticas da administração de recursos federais, quanto da política econômica, não aconteceu o banimento por completo de outras "gramáticas". Em algumas situações o Governo além de recuar estrategicamente em algumas de suas pautas políticas, também foi obrigado a compor alianças com fazedores da política "clientelista", mesmo que não fosse o viés da ideologia militar. O atrelamento de cargos aos políticos locais sempre esteve presente, independente das fases democráticas ou não. E trouxe 
fragilidades, assim como aponta Myrdal (1965), quando analisa a organização política nos países coloniais como o Brasil:

Democrático, oligárquico ou ditatorial, o Estado do qual se espera a elaboração e a execução de todo esse planejamento é, muitas vezes, fraco nos países subdesenvolvidos. Além disso, é servido por uma administração relativamente ineficaz e, algumas vezes, corrupta. É, de modo particular, fraco no nível estadual e municipal.

A era pós-constituição de 1988, que é o maior pano de fundo desse artigo, traz uma tentativa de redemocratização, mas também carrega todo um legado das gramáticas políticas já enraizadas culturalmente. A nova Constituição Federal trouxe o pacto federativo. Com ele a municipalização e conforme Carvalho (2011), o aumento da descentralização do País e uma maior autonomia financeira aos Municípios, que passaram a receber uma quantia bem superior por parte da União. $\mathrm{O}$ que seria para brindar a ordenação das finanças públicas em vistas de garantir o melhor atendimento ao bem comum, na verdade serviu de adubo ao clientelismo e a toda má sorte que ele pode ocasionar em uma administração pública local. A dependência que a maioria dos municípios criou, a partir da emancipação, dos repasses dos Estados e da União, coloca em xeque não só o desempenho das prefeituras, como também a impessoalidade dos atores públicos envolvidos.

Outro viés de discussão é a questão da participação dos entes federativos na vontade Federal. Aos Estados Membros foi concedido o Senado Federal, com representação partidária, podendo inclusive apresentar emendas à Constituição Federal, remetendo ao principio da igualdade jurídica. Mas, apesar de representarem a localidade, segundo Mendes et al (2015):

Observa-se, entretanto, um afastamento das câmaras altas dos Estados federais dessa primitiva intenção motivadora da sua criação. Na medida em que os partidos, que são nacionais galvanizam os interesses políticos, passam a deixar em segundo plano, também, os interesses meramente regionais, em favor de uma orientação nacional, sobretudo partidária.

Mais uma vez a descentralização de poder na busca de viabilizar uma eficácia na gestão pública local é abafada por interesses políticos alheios a todo esse contexto. A orientação partidária, por vezes foca em questões que remetam a garantia de sua sobrevivência, mesmo que tais atos sejam em detrimento de melhorias locais. Assim como observa Michels (1982): “Todos os partidos perseguem atualmente um objetivo parlamentar. Sua atividade evolui sobre o terreno eleitoral e legalitário; seu fim imediato consiste na aquisição de uma influência parlamentar e seu fim último no que chamamos a 'conquista dos poderes públicos'”. Ao mesmo tempo em que interesses partidários nacionais se avultam, tem-se, a questão individual de cada político: 
$\mathrm{Na}$ apresentação dos candidatos políticos se manifesta ainda um outro fenômeno oligárquico grave: o nepotismo. A escolha de candidatos depende quase sempre de uma pequena coligação formada por chefes e subchefes locais que impõem à maioria dos camaradas seus próprios candidatos. Em muitos casos, o colégio eleitoral é considerado simplesmente uma propriedade de família.

Em suma, o que se tem por fim, são interesses partidários nacionais em conchavos políticos com candidatos locais, onde as negociações de cunho eleitoreiro, clientelista e alheias a real necessidade das localidades, acabam sendo e fazendo as Leis, ou as gerenciando a seu bel-prazer. Essa relação do Estado com a Sociedade além de ser uma gramática política, acaba sendo um "sistema". E "nas lutas que os diferentes chefes travam pela hegemonia, o principio democrático torna-se um simples engodo destinado a atrair e a seduzir as massas." Assim disse Michels (1982), de forma generalizada, mas que também cabe aqui a analogia à Constituição Democrática e sua nova proposta de pacto federativo.

\section{PACTO FEDERATIVO NO BRASIL: SUAS \\ PECULIARIDADES E PROBLEMÁTICAS}

O Pacto Federativo, ou, como chamado atualmente, o Federalismo Fiscal, está definido na Constituição da República Federativa do Brasil nos artigos 145 a 162. Entre outros temas, são definidas as competências tributárias dos entes da Federação, e os encargos ou serviços públicos pelos quais são responsáveis. Em outras palavras é a expressão financeira do Federalismo político.

Conforme disposição constitucional, numa federação a hierarquia do poder central para com os entes federados pode ou não acontecer e a autonomia destes pode ter várias magnitudes. No Brasil a tradição é a centralização de poder na União, o que pode ser justificável pela formação do Federalismo brasileiro, originado por desagregação, ou seja, era um Estado unitário que se separou e formou um Estado Federal dando autonomia aos entes periféricos. No rearranjo constitucional do Brasil, para os Estados ficaram as competências que não são apreciadas pelo Governo Federal e não são vetadas pela Constituição. Em relação ao Município, a Constituição inovou, classificando-o como um dos entes integrantes da Federação. Os Municípios legislam sobre matéria de interesse local, além de complementar, quando necessário, a legislação federal e estadual. O Distrito Federal por não se dividir em municípios recebeu da Constituição de 1988 ampla autonomia, igualmente aos demais entes da Federação, tendo no geral as mesmas competências reservadas aos Estados e Municípios.

Pretendeu-se com o pacto federativo no Brasil, uma mescla de federalismo cooperativo e competitivo. Mas tal proposta não logrou de todo êxito, pois a maior característica do Federalismo Fiscal brasileiro é segundo Reverbel (2011), existir um cenário de forte desequilíbrio entre 
a geração de receitas e as responsabilidades dos Estados e Municípios na esfera administrativa. De um lado, uma demasiada centralização reguladora e arrecadatória e, de outro, uma excessiva descentralização político-administrativa. Por essa razão a ideia de um Federalismo cooperativo não é realizável. Já a questão da competição, conforme Bachur (2005) é bastante aguçada entre os entes, principalmente os de mesmo nível, mas como é "uma prática competitiva permitida pelas lacunas institucionais: em função dos interstícios não regulamentados, não é possível articular a cooperação e prevalece uma competição que, por não contar com balizas constitucionais bem definidas, degenera em predação". Então se pode entender que o federalismo brasileiro, o qual pretendia ser um misto de cooperativo com dual (competitivo), vem sendo influenciado pelos mecanismos regulatórios constitucionais que engessam os dois modelos, portanto na prática não se efetivam, como confirma Reverbel (2011): "O que se pretendia federalizar com a Constituição de 1988, acabou, em verdade, se unitarizando, ou descentralizando aos municípios: o verdadeiro nome sem a realidade". Assim é inegável a ampla dependência que a maioria dos municípios possui dos repasses de Estados e da União e como o desempenho de muitas prefeituras dependem da garantia da estabilidade nessa relação.

O federalismo à luz da teoria normativa tem três pilares a serem seguidos por um país como o Brasil, de imensa extensão territorial e de enormes diferenças regionais, que precisa ganhar maior governança investindo na gestão local. De forma a se conseguir eficiência nas funções político-administrativas, um dos focos da teoria normativa é distribuir racionalmente, entre os entes, as competências tributárias. Já as responsabilidades no tocante à provisão de bens públicos, também precisam ser focalizadas, pois ao delegar aos entes a questão financeira é a provisão de bens à sociedade de sua região demográfica a prioridade. E o terceiro pilar tem vistas nos desequilíbrios e na forma de ajustá-los, deste modo quando há diferença entre a capacidade de tributar e a de gastar surgem as transferências intergovernamentais. Baseado na boa teoria normativa, o federalismo fiscal brasileiro usa as transferências de receita tributária entre os três níveis de governo, previstas na $\mathrm{CF}$, para garantir uma maior autonomia financeira dos Governos subnacionais em relação ao Governo central. A ideia é estabelecer um equilíbrio entre as obrigações de cada esfera administrativa e as respectivas necessidades de financiamento. Porém o que se verifica é o uso excessivo de Transferências Governamentais e os municípios sem capacidade de obter escala de produção de serviços suficiente, a provocar um ciclo vicioso na dependência dos repasses da União. Ligação essa que é mote para práticas reconhecidamente clientelistas. Pois, como diagnosticou muito bem Nunes (2003): "o clientelismo se baseia em um conjunto de redes personalistas que afetam os partidos políticos, burocracias e cliques". Abarca uma pirâmide de relações que cruzam de cima a baixo toda sociedade. As elites políticas se amparam numa complexa rede de corretagem política que vai dos altos escalões até as localidades. Nesse 
ínterim, tem papel fundamental os recursos financeiros do Estado para a manutenção e operação do sistema. Partidos políticos que apoiam o governo se favorecem e tem inúmeras prerrogativas por meio do aparelho de Estado. Privilégios que vão desde a criação de empregos até a distribuição de outras benesses de cunho eleitoreiro (pavimentação, construção de escola, etc.) ou ainda recomendação a cargos públicos. Os "corretores" mais importantes tem ingresso facilitado ao centro do Poder. E o que pareceria apenas desequilíbrios falhos do federalismo, se constitui em falta de governabilidade e governança, motivada pela velha corrupção e seus tentáculos, como o patrimonialismo, o nepotismo, e tantos ismos que minam a capacidade local de responder as demandas sociais mais básicas. A confirmação dessas impressões está na relação entre a recente municipalização e as prefeituras mais falidas que bem sucedidas.

\section{MUNICIPALIZAÇÃO, SUA RELAÇÃO COM O FUNDO DE PARTICIPAÇÃO DOS MUNICÍPIOS E OUTRAS NUANCES}

A Constituição Federal de 1988 trouxe como inovação a elevação dos Municípios à categoria de entes federativos, dando-lhes ampla autonomia política, administrativa e financeira. Esse fenômeno conhecido como municipalização, fez parte do desafio de se reconstruir uma ordem democrática após anos de autoritarismo do Regime Militar.

O processo de emancipação dos Municípios brasileiros principiou na década de 30 e sua intensificação ocorreu nas décadas de 50 e 6o, sendo fortemente restrito nas de 70 e 80 pela Constituição Federal de 1967 e normas afins, como aponta Magalhães (2013). Mas com o advento da Constituição Federal de 1988, a "Constituição Cidadã", ocorreu uma nova disposição da estrutura federativa brasileira, que beneficiou as unidades subnacionais, tanto pelo resgate de competências retiradas pelo regime militar, quanto pela criação de novos mecanismos de autonomia política, principalmente no caso dos municípios. Ao se estabelecer um novo pacto federativo, além de fundamentar as bases do Estado democrático, deu-se aos municípios a mais ampla autonomia política da história republicana do Brasil. Tal autonomia pressupõe repartição de competências tomando-se como referência o princípio da predominância do interesse, cabendo à união o interesse geral, aos estados-membros o interesse regional, aos municípios o interesse local e ao distrito federal os interesses regional e local. $\mathrm{O}$ artigo 30 da Constituição Federal fala da competência municipal, dando essa ênfase: "Os Municípios têm competências privativas associadas a serviços públicos de caráter local", tais como o transporte coletivo, por exemplo. As normas constitucionais antes de 1988 delegava aos Estados o poder de organizar e garantir a autonomia dos Municípios. Com o novo texto cabe às municipalidades total emancipação. Essa autonomia dada as comunas alcança quatro níveis: Auto-organização, através da Lei orgânica municipal, onde a forma de governo e sua estruturação estão dispostos; Autolegislação, com a criação de suas próprias Leis munici- 
pais, obedecendo ao limite da Constituição Federal; Autogoverno, com o prefeito (chefe do executivo) e a câmera municipal; e Auto administração, através da máquina administrativa para prestação de serviços públicos ligado ao poder executivo.

A Autonomia Financeira e orçamentária, que dá capacidade ao município de financiar os gastos públicos, tem como finalidade colocar o orçamento a serviço de uma melhor qualidade de vida para os cidadãos. Mas ambas são relativizadas a Lei Complementar n⿳0 101, a Lei de Responsabilidade, que impõe tetos de gastos e controle orçamentário. Para lhe dar com essa autonomia financeira, o município conta com a arrecadação de impostos, além de parcela das receitas federais arrecadadas pela União, que é repassada aos Municípios, conforme tabelas 1 e 2:

TABELA 1

\begin{tabular}{c|c|c} 
ENTE & IMPOSTO & OFERTA \\
Municípios & ITBI, IPTU E IS & $\begin{array}{r}\text { Iluminação e pavimentação pública, } \\
\text { transporte público, etc. }\end{array}$
\end{tabular}

TABELA 2 - Fluxo das Transferências Constitucionais

\begin{tabular}{|c|c|}
\hline ORIGEM/DESTINO & RECEITA TRANSFERIDA \\
\hline \multirow{4}{*}{$\begin{array}{l}\text { UNIÃo para } \\
\text { MUNICÍPIOs }\end{array}$} & $22,5 \%$ do IR e do IPI (FPM) \\
\hline & $70 \%$ do IOF-Ouro \\
\hline & $50 \%$ do ITR \\
\hline & Imposto de renda retido na fonte dos servidores municipais \\
\hline \multirow{2}{*}{$\begin{array}{l}\text { ESTADOs para } \\
\text { MUNICÍPIOS }\end{array}$} & $50 \%$ do IPVA \\
\hline & $25 \%$ do ICMS \\
\hline
\end{tabular}

A criação das transferências governamentais tem como finalidade sanar desequilíbrios e corrigi-los por intermédio de uma equalização fiscal. Podem ocorrer desequilíbrios verticais (resultante de consideráveis desigualdades entre as fontes de receitas e obrigações de despesas entre os governos de uma Federação) e desequilíbrios horizontais (desigualdades de receitas e despesas analisadas entre unidades federativas do mesmo nível), Enap (2018). Assim, o rateio da receita proveniente da arrecadação de impostos entre os entes federados representa um mecanismo fundamental para amenizar as desigualdades regionais, na busca incessante de promover o equilíbrio socioeconômico entre Estados e Municípios. Tesouro Nacional, (2018). Então junto com a autonomia municipal veio a facilidade de incentivos financeiros e a ajuda do Fundo de Participação dos Municípios - FPM.

As transferências de recursos entre os entes da federação estão presentes desde a Constituição de 1934, pelo caráter cooperativista que se tentou dar à federação brasileira. Mas após a Constituição democrática houve uma expansão considerável nessa sistemática. E os municípios são agraciados com repasses tanto pela União, como pelos 
Estados, provenientes do Imposto sobre operações financeiras - IOF (Ouro), Imposto sobre a propriedade Territorial Rural - ITR, Imposto sobre Propriedade de Veículos Automotores - IPVA, Imposto sobre Circulação de Mercadorias e Serviços - ICMS, Fundo de Participação dos Municípios - FPM, e do Fundo de Manutenção e Desenvolvimento da Educação Básica e de Valorização dos Profissionais da Educação - FUNDEB.

FIGURA 1 - Série histórica de emancipação de municípios

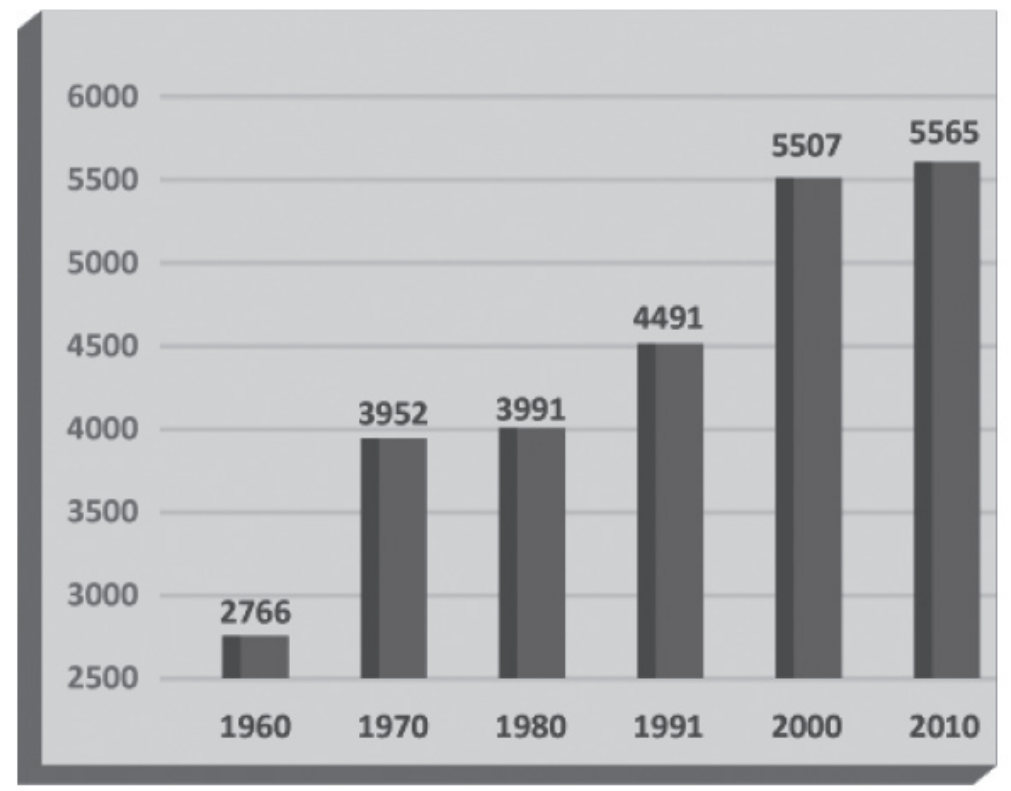

FONTE: IBGE.

De todos os repasses, segundo Brandt (2010), o que mais motivou a elevada emancipação municipal foi o Fundo de Participação dos Municípios - FPM. A administração dos recursos do fundo seria o pretexto econômico maior para a ascensão de novos municípios brasileiros.

O fundo teve origem na Emenda Constitucional no ${ }^{\circ}$ 18, de 1965, em seu artigo 21. A regulamentação do FPM veio com o Código Tributário Nacional (CTN - Lei 5.172, de 25 de outubro de 1966), no seu artigo 91, e o início de sua distribuição deu-se em 1967. O critério inicial de distribuição do FPM era baseado unicamente na população dos Municípios. Ao longo do tempo ocorreram diversas alterações na legislação referente ao Fundo, grande parte ligada ao percentual da arrecadação do IR e do IPI reservado ao FPM. Os percentuais individuais de participação dos Municípios são calculados anualmente pelo Tribunal de Contas da União e por ele publicados em Decisão Normativa no Diário Oficial da União até o último dia útil de cada exercício (CTN, art. 92). Nos critérios são considerados 3 (três) classes de municípios brasileiros: as capitais são Brasília e as capitais estaduais; os do Interior são os demais Municípios que não são capitais; já os Municípios da Reserva são aqueles com população não superior a 142.633 habitantes. Os critérios para cálculo do coeficiente sofre variação conforme cada classificação. 
FIGURA 2 - Classificação dos Municípios brasileiros para efeito do FPM

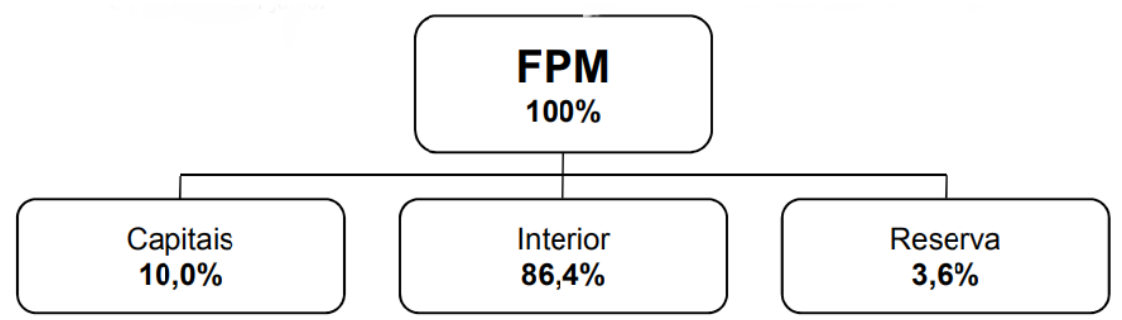

FONTE: Tesouro Nacional. www.tesouro.fazenda.gov.br

Existem dois desvios evidentes na metodologia de cálculo do FPM. Os pequenos Municípios e capitais recebem mais repasses e a faixa intermediária recebe menos. Quem mais leva vantagem são os Municípios com menos habitantes, especialmente tratados de municípios reservas. Isso acontece porque os coeficientes não crescem nas mesmas proporções que as faixas populacionais, desta forma, as Municipalidades menores recebem maiores cotas de repasses per capita em comparação com as demais, inclusive com de algumas capitais.

A maior parte dos municípios criados após 1988 depende categoricamente das transferências federais para desempenhar suas funções. A sua receita tributária arrecadada é insuficiente para pagar até os cargos políticos gerados pela emancipação (prefeitos, vereadores, secretários municipais, etc.). Além disso, normalmente, a atividade econômica nesses municípios não tem sustentabilidade e por isso também não são fontes geradoras de impostos, tornando inócua a participação direta nos tributos estaduais e federais. Tem-se também a questão da qualidade do chefe do executivo à frente dessas prefeituras. Em muitos casos eles não dominam a ciência da Gestão Pública e da boa governança, nomeando por indicação e não por competência seus cargos decisórios. Por fim, nutrem a cultura clientelista em detrimento de uma Administração Pública capaz e eficiente, que saiba gerir os recursos públicos. Muitos prefeitos, não conseguem fazer, por exemplo, investimentos municipais em infraestrutura, para que mais e melhores empresas sejam atraídas para a localidade e tragam geração de impostos. Deste modo, é o FPM que afiança a sobrevivência da maior parte desses entes recém-emancipados. A julgar que, quanto menos populoso for o Município, maior é a vantagem financeira proporcional. A população de um pequeno Município, acaso resolva se dividir em duas, será recebedora do dobro de recursos. A mesma metodologia se repete nos Municípios maiores, mas em menor proporção. Por isso a influência emancipacionista foi justamente para criar municipalidades com menos de 10.000 (dez mil) habitantes. Em virtude disso, o FPM é um tipo de receita considerado aqui, um mecanismo institucional, que instiga as emancipações municipais. O poder local e seu eleitorado depositam na garantia dos recursos provenientes do FPM uma das principais motivações às emancipações. E acaba também, por tabela, a servir de moeda de troca, para que o poder central abasteça suas bases eleitorais. Não é à toa que desde 1988 até agora foram criados mais de 
1600 municípios. A maioria não pela evolução natural da população e a necessidade de ser visto como cidade, mas uma jogada atrelada ao FPM e a vantagem que ele oferece no repasse de recursos aos municípios anões. Esse processo não teve maiores avanços devido à Emenda Constitucional nº 15/1996, que disciplinou o processo de emancipação.

$\mathrm{Na}$ análise de indicadores sociais municipais, baseado no censo de 2000, o Instituto Brasileiro de Geografia e Estatística - IBGE aponta que a grande maioria dos municípios criados entre 1991 e 2001 não ultrapassa o limite de 5000 (cinco mil) habitantes, representando $57 \%$ do total dos municípios novos no período. Entre 5000 (cinco mil) e 10000 (dez mil) habitantes, foram criados 280 ( $26,2 \%$ do total) e na faixa de 10000 (dez mil) a 20000 (vinte mil) residentes, encontram-se $13 \%$ dos novos municípios. Logo, cerca de $96 \%$ dos municípios criados entre 1991 e 2000 possuem até 20000 (vinte mil) habitantes. Em relação ao Fundo de Participação dos Municípios, as cidades abaixo de 20000 (vinte mil) habitantes são isentas, pela Constituição Federal, a ter um plano diretor no auxílio da administração do fundo. Em contrapartida, conforme o IBGE (2018), em 2015, em 3.170 municípios (56,9\% dos municípios brasileiros) a atividade econômica predominante era a Administração Pública, defesa, educação e saúde públicas e seguridade social. Mais de 90\% dos municípios dos estados da Paraíba, do Amapá, Roraima, Piauí e Ceará tinham esse perfil e, de forma oposta, aproximadamente $11 \%$ dos municípios da região Sul apresentavam essa característica. Notoriamente nas estatísticas existe a dependência e sobrevivência dos repasses da União e dos Estados. Os municípios não possuem Produto Interno Bruto com foco em atividades econômicas. Isso gera um ciclo vicioso sem precedentes, agravado com a chancela da Constituição Federal, para a ingerência deste fundo em municípios, quando isenta a necessidade de gestão do mesmo em municipalidades com menos de 20000 (vinte mil) habitantes. É urgente e imperiosa a revisão do pacto federativo e na forma como a questão tributária está sendo conduzida e gerida. Conforme Conti (2004), necessita-se a reestruturação das competências tributárias, transferindo "bases de incidência" como a de serviços (ISS) para a União Federal, em troca de transferências fiscais amparadas em critérios que meçam o esforço fiscal de cada ente. Como também é imperiosa a necessidade de revisão nos mecanismos constitucionais que "favorecem" a prática clientelista e corporativista.

\section{BREVE ANÁLISE DOS MUNICÍPIOS PERNAMBUCANOS PÓS CF 1988}

O Estado de Pernambuco, não diferente dos demais, teve criação de municípios pós Constituição Cidadã. Exatamente 18 novas cidades surgiram, sendo elas: Carnaubeiras da Penha; Dormentes; Fernando de Noronha; Jucati; Lagoa do Carro; Quixaba; Santa Cruz; Santa Cruz da Baixa Verde; Vertente do Lério; Xexéu; Araçoiaba; Casinhas; Jaqueira; Jatobá; Lagoa Grande; Manari; Santa Filomena; Tamandaré.

$\mathrm{O}$ artigo nesse momento se propõe a análise de alguns indicadores socioeconômicos dessas localidades, como diagnóstico do sucesso 
da sua autonomia enquanto ente federativo e do impacto do poder local em servir ao cidadão com eficiência. Para tanto serão analisados dois dos maiores e mais importantes índices sociais: o Índice de Desenvolvimento Humano Municipal - IDHM e o coeficiente de GINI. Num recorte temporal de uma década, uma vez que os indicadores só estão disponíveis para os municípios a partir de 2000. O IDHM é um indicador sintético com objetivo de servir como referência para o nível de desenvolvimento humano de um determinado local. $O$ índice varia entre o (valor mínimo) e I (valor máximo). Composto por indicadores de saúde, educação e renda. Na perspectiva que pessoas precisam ter a possibilidade de levar uma vida longa e saudável, acesso a conhecimento e oportunidade de desfrutar de um padrão de vida digno. O IDHM é a adaptação do IDH a níveis municipais, com pequenas alterações, e fruto da média geométrica dos três subíndices. Adotam-se pesos iguais na concepção de que as três dimensões são igualmente importantes e não são substituíveis, conforme disposto no Atlas de Desenvolvimento Humano (2018). O GINI é um Indicador Socioeconômico, que mede o grau de desigualdade na distribuição da renda domiciliar per capita entre os indivíduos. Seu valor pode variar teoricamente desde o, quando não há desigualdade (as rendas de todos os indivíduos têm o mesmo valor), até 1, quando a desigualdade é máxima (apenas um indivíduo detém toda a renda da sociedade e a renda de todos os outros é nula), dados do Instituto de Pesquisa Econômica Aplicada - Ipeadata (2018).

TABela 3 - Munícipios Pernambucanos Emancipados pós 1988 Índice de Desenvolvimento Humano Municipal

\begin{tabular}{l|c|c|c|c|c|c}
\multicolumn{1}{c|}{ MUNÍCIPIO } & IDHM & IDHM & TX\% & HIATO & HIATO & $\begin{array}{c}\text { TX\% } \\
\text { Fernando de Noronha }\end{array}$ \\
\hline Jatobá & 0,690 & 2010 & VARIAÇÃO & 2000 & 2010 & VARIAÇÃO \\
\hline Lagoa do Carro & 0,782 & $14 \%$ & 0,306 & 0,212 & $-69 \%$ \\
\hline Lagoa Grande & 0,493 & 0,609 & $22 \%$ & 0,471 & 0,355 & $-53 \%$ \\
\hline Santa Cruz da Baixa Verde & 0,493 & 0,597 & $21 \%$ & 0,507 & 0,403 & $-49 \%$ \\
\hline Araçoiaba & 0,474 & 0,612 & $29 \%$ & 0,526 & 0,388 & $-47 \%$ \\
\hline Casinhas & 0,429 & 0,592 & $38 \%$ & 0,571 & 0,408 & $-43 \%$ \\
\hline Dormentes & 0,417 & 0,567 & $36 \%$ & 0,583 & 0,433 & $-42 \%$ \\
\hline Tamandaré & 0,403 & 0,589 & $46 \%$ & 0,597 & 0,411 & $-40 \%$ \\
\hline Quixaba & 0,402 & 0,593 & $48 \%$ & 0,598 & 0,407 & $-40 \%$ \\
\hline Jaqueira & 0,394 & 0,577 & $46 \%$ & 0,606 & 0,423 & $-39 \%$ \\
\hline Vertente do Lério & 0,394 & 0,575 & $46 \%$ & 0,606 & 0,425 & $-39 \%$ \\
\hline Jucati & 0,382 & 0,563 & $47 \%$ & 0,618 & 0,437 & $-38 \%$ \\
\hline Xexéu & 0,373 & 0,55 & $47 \%$ & 0,627 & 0,45 & $-37 \%$ \\
\hline Santa Cruz & 0,365 & 0,552 & $51 \%$ & 0,635 & 0,448 & $-37 \%$ \\
\hline Carnaubeiras da Penha & 0,341 & 0,549 & $61 \%$ & 0,659 & 0,451 & $-34 \%$ \\
\hline Santa Filomena & 0,315 & 0,573 & $73 \%$ & 0,669 & 0,427 & $-33 \%$ \\
\hline Manari & 0,295 & 0,487 & $65 \%$ & 0,705 & 0,513 & $-30 \%$ \\
\hline
\end{tabular}

FONTE: Elaboração própria. Dados extraídos atlas do desenvolvimento humano. http:// atlasbrasil.org.br 
FIGURA 3 - Municípios pernambucanos criados a partir de 1988, amostra comparativa entre o IDHM de cada município e o da Capital Recife.

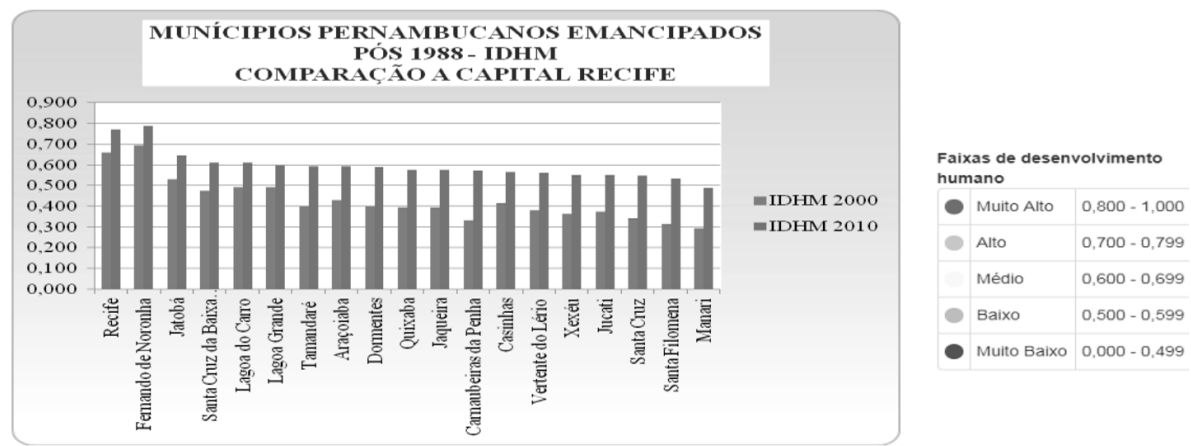

FONTE: Elaboração própria - dados extraídos atlas do desenvolvimento humano

Dos 18 (dezoito) municípios no ano de 2000, conforme tabela 3, apenas 1 (um) ficou na faixa de desenvolvimento humano considerado médio. Apenas 1 (um) na faixa considerado baixo e 16 (dezesseis) municípios na pior faixa do IDHM, considerado muito baixo. Inclusive o município de Manari, conforme o site atlas do desenvolvimento humano, é o pior IDHM do estado no período. Em 2010 houve uma taxa de aumento de até $73 \%$ em relação à década anterior, mas mesmo assim, dos 18 (dezoito) municípios 1 (um) está na faixa considerado alto, 3 (três) na faixa de performance média, 13 (treze) na faixa considerado IDHM baixo e 1 (um) ainda considerado muito baixo. Em dez anos apenas um município conseguiu um bom desempenho nas variáveis sociais monitoradas pelo IDHM. Os demais municípios apesar de aumento não tiveram pontuação nos índices que pudessem comprovar que estão ofertando aos seus moradores condições de vida dignas para justificar a emancipação, ou a boa gerência das transferências governamentais.

TABELA 4 - Frequência Relativa e Absoluta (HIATO IDHM)

\begin{tabular}{l|r|r|r|r} 
& 2000 & 2010 & 2000 & 2010 \\
\hline Histograma & \multicolumn{2}{|c|}{ FA } & \multicolumn{2}{|c}{ FR\% } \\
\hline $0,000-0,200$ & 0 & 0 & $0 \%$ & $0 \%$ \\
\hline $0,201-0,300$ & 0 & 1 & $0 \%$ & $6 \%$ \\
\hline $0,301-0,400 t$ & 1 & 3 & $6 \%$ & $17 \%$ \\
\hline $0,401-0,500$ & 1 & 13 & $6 \%$ & $72 \%$ \\
\hline $0,501-1,0$ & 16 & 1 & $89 \%$ & $6 \%$ \\
\hline Total & 18 & 18 & $100 \%$ & $100 \%$ \\
& FONTE: Elaboração Própria
\end{tabular}

Na tabela 4, confirmando o péssimo desempenho dos municípios, tomando por base o IDHM ideal, foi analisado o hiato de desenvolvimento humano (distância entre o IDHM do município e o limite máximo do índice, que é 1). Pode-se notar que a variação dos indicadores para chegar ao seu ótimo não oscilou significativamente na maioria dos casos, no ano de 2000 quase a totalidade $(89 \%)$ dos municípios tiveram hiatos acima de meio ponto. Após uma década, em 2010, houve 
uma variação e apenas $6 \%$ das municipalidades permaneceram com hiatos acima de $0,500.72 \%$ tiveram hiatos oscilando na média de meio ponto. Apenas $22 \%$ conseguiram diminuir o hiato de forma a obter menos de 0,500, mas nada considerada uma performance excepcional, uma vez que apenas um município teve hiato menor que o,300.

Na figura 3, uma comparação à capital pernambucana, mostra que apenas um município possui desempenho igualável ou superior. É o município de Fernando de Noronha, que tem destaque por sua capacidade turística, ao mesmo tempo em que não possui muitos habitantes pelas restrições ambientais impostas. Um caso que não é exatamente referência, uma vez que não se confronta com a realidade dos demais municípios.

TABela 5 - Munícipios Pernambucanos Emancipados pós 1988 Índice de Gini da Renda Domiciliar per Capita

\begin{tabular}{|c|c|c|c|c|c|c|c|c|c|}
\hline MUNÍCIPIO & $\begin{array}{l}\text { GINI } \\
2000\end{array}$ & $\begin{array}{l}\text { GINI } \\
2010\end{array}$ & $\begin{array}{c}\% \\
\text { VARIAÇÃO }\end{array}$ & $\begin{array}{c}X \\
\text { RECIFE }\end{array}$ & $X N E$ & $\begin{array}{c}\mathrm{x} \\
\text { BRASIL }\end{array}$ & $\begin{array}{c}X \\
\text { RECIFE }\end{array}$ & $X N E$ & $\begin{array}{c}\mathrm{x} \\
\text { BRASIL }\end{array}$ \\
\hline Recife & 0,68 & 0,69 & \multirow{3}{*}{\multicolumn{7}{|c|}{$\frac{\text { COMPARAÇÃO GINI MUNICÍPIO VERSUS GINI }}{\underline{\text { RECIFE, NORDESTE E BRASIL }}}$}} \\
\hline Nordeste & 0,61 & 0,55 & & & & & & & \\
\hline Brasil & 0,60 & 0,53 & & & & & & & \\
\hline $\begin{array}{l}\text { Fernando de } \\
\text { Noronha }\end{array}$ & 0,50 & 0,46 & $-8 \%$ & $-26 \%$ & $-18 \%$ & $-50 \%$ & $-33 \%$ & $-54 \%$ & $-13 \%$ \\
\hline Jatobá & 0,54 & 0,58 & $7 \%$ & $-20 \%$ & $-11 \%$ & $-46 \%$ & $-20 \%$ & $-42 \%$ & $9 \%$ \\
\hline $\begin{array}{l}\text { Santa Cruz da } \\
\text { Baixa Verde }\end{array}$ & 0,53 & 0,51 & $-4 \%$ & $-22 \%$ & $-13 \%$ & $-47 \%$ & $-34 \%$ & $-49 \%$ & $-4 \%$ \\
\hline $\begin{array}{l}\text { Lagoa do } \\
\text { Carro }\end{array}$ & 0,56 & 0,46 & $-19 \%$ & $-18 \%$ & $-8 \%$ & $-44 \%$ & $-51 \%$ & $-55 \%$ & $-14 \%$ \\
\hline Lagoa Grande & 0,51 & 0,50 & $-2 \%$ & $-24 \%$ & $-16 \%$ & $-49 \%$ & $-32 \%$ & $-50 \%$ & $-5 \%$ \\
\hline Tamandaré & 0,63 & 0,56 & $-11 \%$ & $-8 \%$ & $3 \%$ & $-37 \%$ & $-26 \%$ & $-44 \%$ & $5 \%$ \\
\hline Araçoiaba & 0,56 & 0,52 & $-8 \%$ & $-17 \%$ & $-8 \%$ & $-44 \%$ & $-38 \%$ & $-48 \%$ & $-2 \%$ \\
\hline Dormentes & 0,57 & 0,47 & $-17 \%$ & $-16 \%$ & $-7 \%$ & $-43 \%$ & $-44 \%$ & $-53 \%$ & $-11 \%$ \\
\hline Quixaba & 0,74 & 0,49 & $-33 \%$ & $9 \%$ & $21 \%$ & $-26 \%$ & $-35 \%$ & $-51 \%$ & $-7 \%$ \\
\hline Jaqueira & 0,54 & 0,59 & $9 \%$ & $-21 \%$ & $-12 \%$ & $-46 \%$ & $-19 \%$ & $-41 \%$ & $11 \%$ \\
\hline $\begin{array}{l}\text { Carnaubeiras } \\
\text { da Penha }\end{array}$ & 0,61 & 0,57 & $-7 \%$ & $-10 \%$ & $0 \%$ & $-39 \%$ & $-26 \%$ & $-43 \%$ & $7 \%$ \\
\hline Casinhas & 0,60 & 0,45 & $-25 \%$ & $-11 \%$ & $-1 \%$ & $-40 \%$ & $-48 \%$ & $-55 \%$ & $-14 \%$ \\
\hline $\begin{array}{l}\text { Vertente do } \\
\text { Lério }\end{array}$ & 0,59 & 0,45 & $-23 \%$ & $-13 \%$ & $-4 \%$ & $-41 \%$ & $-40 \%$ & $-55 \%$ & $-15 \%$ \\
\hline Xexéu & 0,51 & 0,50 & $-3 \%$ & $-24 \%$ & $-16 \%$ & $-49 \%$ & $-33 \%$ & $-50 \%$ & $-6 \%$ \\
\hline Jucati & 0,54 & 0,51 & $-4 \%$ & $-21 \%$ & $-12 \%$ & $-46 \%$ & $-39 \%$ & $-49 \%$ & $-3 \%$ \\
\hline Santa Cruz & 0,72 & 0,57 & $-21 \%$ & $6 \%$ & $18 \%$ & $-28 \%$ & $-27 \%$ & $-43 \%$ & $7 \%$ \\
\hline $\begin{array}{l}\text { Santa } \\
\text { Filomena }\end{array}$ & 0,63 & 0,55 & $-13 \%$ & $-7 \%$ & $3 \%$ & $-37 \%$ & $-28 \%$ & $-45 \%$ & $4 \%$ \\
\hline Manari & 0,71 & 0,54 & $-24 \%$ & $5 \%$ & $17 \%$ & $-29 \%$ & $-28 \%$ & $-46 \%$ & $3 \%$ \\
\hline
\end{tabular}

Fonte: Elaboração Própria - Dados extraídos do Atlas de Desenvolvimento Humano 
A tabela 5 traz uma análise do GINI, no decorrer de dez anos. Esse índice quanto mais próximo de 1 (hum), mais desigual é a localidade e quanto mais próximo de o, menos desigual. Na análise isolada observa-se que na década evidenciada houve uma queda geral do nível de desigualdade. Conforme o site oficial do Governo Federal (www.brasil. gov.br), essa baixa se dá em ocorrência da ampliação dos programas de transferência de renda, como o Bolsa Família, por exemplo, e devido à intervenção do poder central na economia (função distributiva). Esses programas cooperaram na promoção de maior redistribuição de renda e, consequentemente, melhora no indicador. Esse diagnóstico denota que além das transferências orçamentárias, outras receitas também precisam "ajudar" o município a apresentar desenvolvimento. Quando comparado o GINI de cada localidade com os índices da capital Recife, do Nordeste e do Brasil, os municípios estão, de forma generalizada, menos desigual. Essa nuance denota duas características, uma reforça a importância dos programas de transferência de renda em municípios muito pobres e também a falta de habitantes detentores de grandes fortunas ou rendas diferenciadas. $\mathrm{O}$ que não exprime exatamente $\mathrm{o}$ sucesso dos municípios no combate da desigualdade social com seus próprios esforços, haja vista os resultados das apreciações do outro índice.

Na análise seguinte, devido à limitação de laudas do artigo, apenas o município que apresentou o pior desempenho no IDHM - O Índice de Desenvolvimento Humano será avaliado: Manari. Ele obteve em 2010 o indicador de 0,487 , o que situa esse localidade na faixa de Desenvolvimento Humano muito baixo (o,00o - 0,499).

O enfoque dessa apreciação são as transferências governamentais, a arrecadação de imposto e gasto com pessoal. O município no último Censo de 2010 tinha 18.083 habitantes, 4.970 famílias inseridas no Cadastro único, das quais 4.459 recebem até $1 / 2$ salário mínimo e possuía $56,04 \%$ da população beneficiada pelo Bolsa família, conforme dados do Ministério de Desenvolvimento Social.

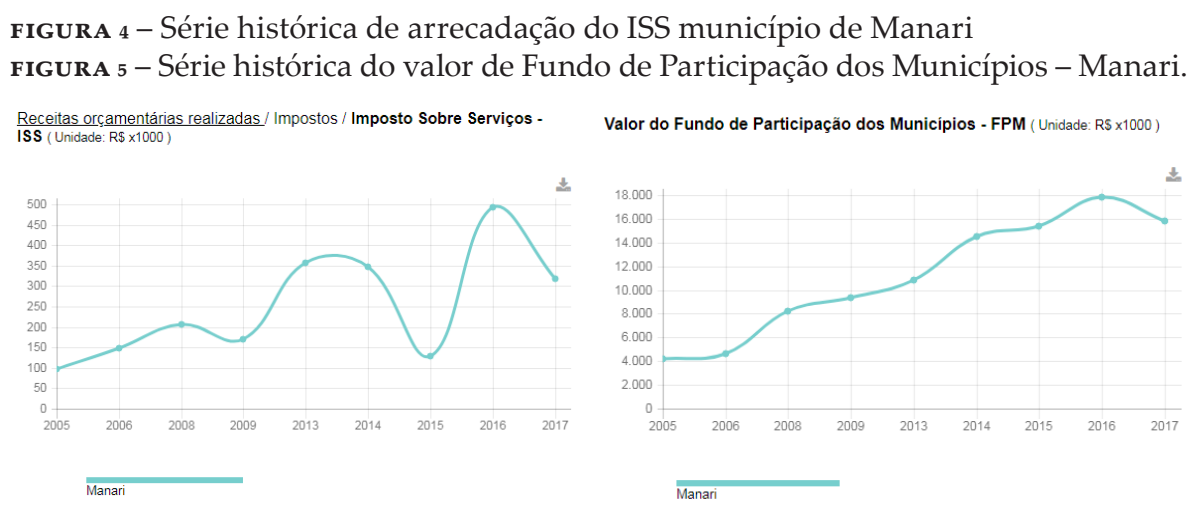

FONTE: IBGE. www.cidades.ibge.gov.brt

Na figura 4, temos a série histórica de 2005 a 2017, da arrecadação do ISS - Imposto sobre Serviços do município de Manari. Oscilando entre $\mathrm{R}$ \$ 100.000,00 e $\mathrm{R}$ \$ 500.000.00, que foi quase o máximo arrecadado 
em 2016. No ano seguinte houve uma considerada queda para casa dos 300 mil. Em contrapartida na figura 5 houve um aumento expressivo, no mesmo espaço temporal, do FPM - Fundo de Participação dos Municípios, que já inicia com cerca de $\mathrm{R} \$$ 4.000.000,00 em 2005 e chega ao pico num valor próximo de $\mathrm{R} \$$ 18.000.000,00 em 2016. Nesse mesmo ano Manari ficou no ranking de beneficiários de PE na posição $95^{\circ}$, dentre os 185 municípios existentes. A fonte de recursos vinda do ISS se apresenta em média menor que 3\% do valor derivado do FPM. Quase irrisório em importância no Orçamento total.

FIGURA 6 - Série histórica do valor de Despesas com Pessoal e encargos sociais do município de Manari (Unidade: $\mathrm{R}$ x1000)
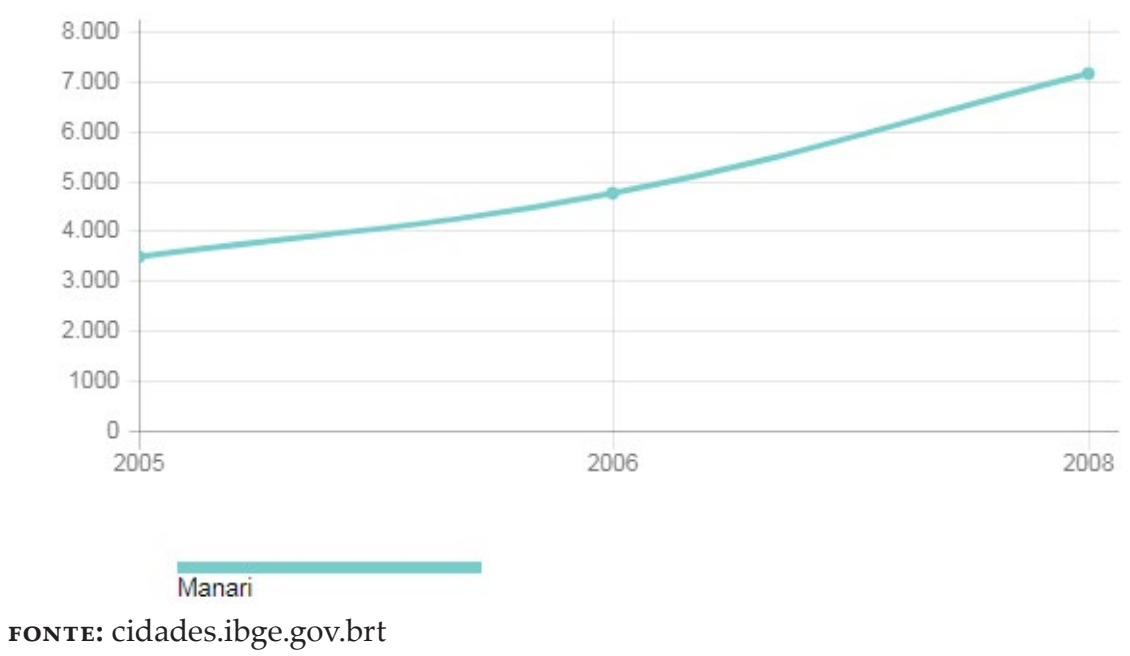

A figura 6, numa série histórica mais curta, demonstra que em 2008, por exemplo, os custos com pessoal e encargos sociais chegaram a quase $\mathrm{R} \$ 3.000 .000,00$. Que se pese o recebimento do ISS, imposto que vem da prestação de serviços no município e denota a capacidade tributária que a localidade possui em uma parte de seu setor terciário, no mesmo ano correspondeu a menos de $7 \%$ dos custos com pessoal. O fôlego financeiro do município denota claramente que não vem de esforços fiscais, mas sim dos repasses da União.

No diagnóstico cruzado entre índices sociais, fundo de participação municipal, imposto de arrecadação local e encargos pessoais, percebe-se claramente, embora sem maiores aprofundamentos, que a decisão de emancipação não vem da capacidade de autogestão do município, nem do potencial do mesmo em movimentar economicamente a localidade. O FPM custeia praticamente sozinho a máquina administrativa, e durante algum tempo se mostrou ineficaz na melhoria das condições de vida dos habitantes. Os índices sociais começaram a reagir coincidentemente com datas de implantação do Bolsa Família. Esses dados não foram estudados nesse artigo, por não ter aderência com o tema, mas injetou na economia local, por exemplo, nos meses de agosto/2018 a setembro/2017 o montante de R $\$ 12.667 .692,00$, segundo dados do Ministério do Desenvolvimento Social. 


\section{CONCLUSÃO}

Esse artigo se propôs a discussão do federalismo brasileiro e a municipalização, tendo como pano de fundo as gramáticas políticas do Brasil. Na análise temporal da República Federativa e todas as Constituições Federais, foi visto um sistema Federal ora com Poder Central, ora descentralizado. Mas independente da constituição desse Poder em determinada época, as gramáticas políticas faziam parte influente do cenário. Pode-se até afirmar após a contenda, que o clientelismo esteve lado a lado com todas as questões que envolveram a evolução do Federalismo Nacional, até os dias atuais.

O pacto federativo trazido pela CF de 1988 e o advento da municipalização, tem falhas estruturais e uma rigidez, onde os entes federativos têm tributos que são de arrecadação exclusiva e Transferências constitucionais mandatórias, com regras bem limitadas. Isso gera problemas de cooperação entre os Entes, principalmente verticalmente e acabam aguçando a competição e a guerra fiscal. Essas situações ferem os princípios federalistas e o pacto perde sua essência de descentralização para combater as desigualdades sociais e regionais.

A municipalização trouxe uma quantidade exorbitante de municípios e micromunicípios, onde grande parte não tem condições de se autossustentar. Problema esse que contribui para a ampliação das disparidades socioeconômicas, uma vez que a criação de municipalidades onera os cofres públicos, gerando diversos gastos sem receita oriunda de arrecadação própria. Recorrendo, num ciclo vicioso, à utilização das receitas de transferências da União, que ao invés de "cobrir" gastos diversos, poderiam ser empregadas em investimentos na saúde, educação, segurança pública, etc e, sobretudo, em infraestrutura para atrair mais pessoas físicas e jurídicas, aumentando as receitas tributárias e a capacidade financeira do município de gerir-se. Além dessa lacuna, preenchida pelo FPM, fomentar redes clientelistas, em uma pirâmide que cruza de alto a baixo a sociedade, ora como moeda de troca para fortalecimento de bases partidárias, ora como uso para fins apenas eleitoreiros, sem grandes benefícios para as localidades.

Por fim, as análises efetuadas nos municípios pernambucanos criados após a CF de 1988, serviram não só para ilustrar a discussão, como também para provar que toda a construção da Constituição Cidadã em relação à adequação do federalismo a vieses democráticos, na verdade não passa de uma falácia. Pois como afirma Michels (1982), quando "os revolucionários" atingem seus ideários, eles não hesitam em modificar sua primeira profissão de fé, declarando-se revolucionários apenas no "melhor sentido da palavra", ou seja, não mais pelos meios que só interessam ao programa, mas unicamente na teoria e no papel. Uma constituição criada com fins democráticos apenas no impresso, mas na prática a "revolução" democrática proposta se tornou a manutenção do bom e velho sistema clientelista, com um federalismo desvirtuado e servindo a poucos. 


\section{REFERÊNCIAS}

Bachur, J. P. (2005, setembro/outubro) Federalismo fiscal, atribuições fiscais constitucionais e equalização regional: EUA, Alemanha e Brasil em perspectiva comparada. Revista do Serviço Público, v. 56, n. 4, p. 377-401.

Benevides, P. (2004) Teoria do Estado. (3a ed.). São Paulo: Impresso no Brasil 01-2007.

Bercovici, G. (2013). O poder constituinte do povo no Brasil: um roteiro de pesquisa sobre a crise constituinte. Recuperado em 24 novembro, 2018, de http://www.scielo.br/pdf/ln/n88/a1on88.pdf

Brandt, C. T, (2010) A criação de municípios após a constituição de 1988. Recuperado em 21 novembro, 2018, de https://www2.senado.leg.br/bdsf/bitstream/ handle/id/198693/ooo897816.pdf?sequence=1

Brito, L. N. Baleeiro, A.(2012) Senado Federal, Subsecretaria de Edições Técnicas. (za ed ). Brasília: Coleção Constituições brasileiras

Carvalho, M. B. (2011) Federalismo: conceitos e origem. [Apostila Curso Federalismo Fiscal]. Brasília:Escola Virtual da SOF

CONTI, J. M. (204.). Federalismo fiscal. São Paulo: Manole

Michels, R. (1982) Sociologia dos partidos políticos. (1a ed.). Brasília: Editora Universidade de Brasília.

Myrdal, Gunnar. (1965) Teoria econômica e regiões subdesenvolvidas. (1a ed.). Rio de Janeiro: Saga

Gadelha, S. R B. (2018). O Caso brasileiro [Apostila do Curso Federalismo Brasileiro]. Brasília: ENAP.

Magalhães, J. C. (2013). Emancipação PolíticoAdministrativa de Municípios no Brasil. Recuperado em 21 de novembro, 2018, de http://ipea.gov.br/agencia/ images/stories/PDFs/livros/Capitulo1_30.pdf

Mendes, G., Coelho, I. M., Branco, P. G. G. (2017) Curso de direito Constitucional. Recuperado em 23 de novembro, 2018, de http://noosfero.ucsal.br/articles/o010/3238/ gilmar-mendes-curso-de-direito-constitucional.pdf Hollanda, S. B. (1997). Raízes do Brasil. (2a ed.). Rio de Janeiro: Raízes do Brasil.

Martins, F. (2017) Curso de Direito Constitucional. (1a ed.). São Paulo: Editora Revista dos Tribunais. 
Nunes, E. O. (2003) A gramática política do Brasil:

Clientelismo, corporativismo insulamento burocrático. (3a ed). Rio de Janeiro: Garamond.

Reverbel, C. E. D. (2011) O federalismo numa visão tridimensional do direito. São Paulo: Editora Livraria do Advogado. 
Revista

dos Mestrados

Profissionais

ISSN: 2317-0115 
Revista

dos Mestrados

Profissionais

ISSN: 2317-0115 